\title{
ANALISIS DAN PERANCANGAN SISTEM INFORMASI PENJUALAN PADA UD RUMPUN TANI
}

\author{
Dita Rizky Ananda ${ }^{1}$, Rini Amalia ${ }^{2}$, Fitria Sari Hasanusi ${ }^{3}$ \\ Program Studi Teknik Informatika, Fakultas Teknik dan Ilmu Komputer, \\ Universitas Indraprasta PGRI \\ Jalan Raya Tengah No 80, Kelurahan Gedong, Pasar Rebo, Jakarta Timur \\ drzkyanandaa@gmail.com ${ }^{1}$, reen.amaleea@gmail.com ${ }^{2}$, hasanfitria26@gmail.com
}

\begin{abstract}
Abstrak
Permasalahan dari sistem penjualan benih sayuran di UD RumpunTani yaitu lambatnya dalam pencarian data barang, proses pembuatan laporan serta sering terjadinya kesalahan perhitungan dalam melakukan proses transaksi yang diakibatkan karena sistem yang diterapkan masih konvensional, yaitu secara tertulis. Seiring dengan berkembangnya teknologi yang semakin canggih, computer telah mendorong terjadinya perubahan ilmu, baik dalam kajian ataupun implementasi dilapangan. Peran teknologi computer sangat diperlukan oleh berbagai perusahaan. Mengingat kebutuhan akan peningkatan efisiensi dan efektivitas dari setiap kegiatan dalam instansi tidak dapat diukur dan dilakukan secara cepat dan akurat tanpa adanya dukungan teknologi tersebut. Akurasi data, kecepatan waktu dan relevansi menjadi penentu kualitas informasi yang dihasilkan. Tujuan dari sistem ini untuk mempercepat dalam pencarian data barang, proses pembuatan laporan serta mengatasi kesalahan perhitungan dalam proses transaksi. Hasil dari penelitian ini yaitu menciptakan aplikasi untuk penjualan benih sayuran yang efektif dan efisien.
\end{abstract}

Kata Kunci: Sistem Informasi, Penjualan, Benih Sayuran, Java

\begin{abstract}
The problem with the vegetable seed sales system at UD Rumpun Tani is the slowness in searching for goods data, the reporting process and the frequent occurrence of calculation errors in processing transactions caused because the system applied is still conventional, namely in writing. Along with the development of increasingly sophisticated technology, computers have encouraged changes in science, both in study and implementation in the field. The role of computer technology is needed by various companies. Considering the need to increase the efficiency and effectiveness of every activity within the agency, it cannot be measured and carried out quickly and accurately without the support of the technology. Data accuracy, speed of time and relevance determine the quality of the information produced. The purpose of this system is to speed up the search for data items, the process of making reports and overcoming calculation errors in the transaction process. The result of this research is to create an application for selling vegetable seeds that is effective and efficient.
\end{abstract}

Keywords: Information System, Sales, Vegetables Seed, Java

\section{PENDAHULUAN}

Dalam dunia bisnis kebutuhan akan teknologi informasi sekarang ini merupakan suatu kebutuhan yang sangat vital. Sebab sudah banyak jalannya bisnis dikendalikan dan tidak terlepas dari teknologi informasi. Bahkan hampir semua bidang sekarang ini mulai menerapkan teknologi informasi dalam pengembangannya, dikarenakan oleh kelebihan-kelebihan yang dimiliki oleh teknologi tersebut yaitu dalam pengolahan data dan penghematan waktu yang digunakan untuk memprosesnya. Banyak perusahaan yang menggunakan sistem informasi yang berbasiskan komputer untuk kelancaran bisnis dan pekerjaan mereka. Salah satu sistem yang digunakan adalah sistem informasi penjualan.

Berdasarkan observasi yang dilakukan, Peneliti mendapatkan bahwa sistem yang digunakan oleh UD.RUMPUN TANI saat ini masih konvensional yaitu dimana pencatatan data persediaan barang dan data transaksi penjualan masih dilakukan secara tertulis. Lalu proses transaksi penjualan yang kurang efektif dan efisien dikarenakan masih menggunakan alat bantu seperti kalkulator, hal ini jugalah yang menyebabkan sering terjadinya kesalahan dalam menjumlahkan total bayar. Tidak hanya itu pengelolaan data persediaan barang juga belum terkontrol dengan baik, menyebabkan terjadinya ketidakcocokan antara data barang yang dibeli dengan data barang yang tersedia, sehingga mempersulit dalam proses pencarian data barang maupun pembuatan laporan persediaan barang. Hal ini terjadi karena pada UD.RUMPUN TANI ini belum mempunyai sebuah sistem 
informasi yang mendukung dalam prosesnya sehingga menyebabkan tidak efektif dan efisiennya kinerja perusahaan. Sehubungan dengan hal diatas yaitu untuk memudahkan pihak perusahaan dan meningkatkan kinerja perusahaan saat ini, pemanfaatan teknologi berupa sistem informasi sangat amat dibutuhkan, maka dari itu peneliti akan merancang sistem informasi penjualan pada UD Rumpun Tani yang terintegrasi, yang dapat mengolah persediaan stok barang secara up to date, serta pengolahan laporan dengan sangat baik, efektif dan efisien.

\section{PENELITIAN YANG RELEVAN}

Penelitian oleh (Rini, 2010) dengan judul Sistem Informasi Penjualan Barang pada Toko Sumber Urip. Hasil dari penelitian tersebut adalah dengan dirancangnya sistem informasi penjualan yang terkomputerisasi dengan tujuan yang diharapkan yaitu untuk mengatasi segala masalah yang ada, contohnya masalah dalam melakukan proses transaksi jual-beli. Sehingga proses transaksi penjualan dapat dilakukan secara efektif dan efisien serta optimal.

Penelitian selanjutnya oleh (Mujiati, 2014) dengan Judul Perancangan Sistem Informasi Stok Obat pada Apotek Arjowinangun. Hasil dari penelitian tersebut adalah dengan dirancangnya aplikasi inventory yang dapat mengelola, mencatat dan memberikan informasi stok obat secara up to date sehingga tidak membutuhkan waktu yang lama serta kekeliruan ketika ingin mendapatkan informasi stok obat.

\section{METODOLOGI PENELITIAN}

\section{Metode Pengupulan Data}

\section{Studi Lapangan (Field Research)}

a. Observasi

Observasi merupakan suatu cara pengumpulan data dengan mengadakan pengamatan langsung terhadap suatu objek dalam suatu periode tertentu dan mengadakan pencatatan secara sistematis tentang hal-hal tentu yang diamati. Peneliti mempelajari dan mengamati proses data transaksi penjualan serta data pengolahan stok yang terjadi di UD. Rumpun Tani.

b. Wawancara

Wawancara merupakan suatu teknik pengumpulan data yang dilakukan dengan cara tanya jawab antara penanya dengan penjawan. Peneliti melakukan wawancara dengan pemilik UD. Rumpun Tani untuk memperoleh keterangan mengenai objek penelitian dan berbagai kebutuhan user yang akan menggunakan sistem.

2. Studi Kepustakaan (Library Research)

Penulis menggunakan teknik pengumpulan data dengan cara studi pustaka, yaitu mengumpulkan data dan mempelajari atau membaca pendapat ahli yang berhubungan dengan permasalahan yang akan diteliti untuk memperoleh data yang diperlukan serta untuk landasan teori yang akurat dan menunjang. Baik bersumber dari buku, makalah, jurnal ataupun dari beberapa sumber internet.

\section{Langkah-Langkah Pengembangan Sistem}

Dalam pembuatan sistem ini penulis menggunakan metode pengembangan sistem yaitu metode Waterfall (Pressman, 2012), dengan tahapan-tahapan seperti gambar sebagai berikut:

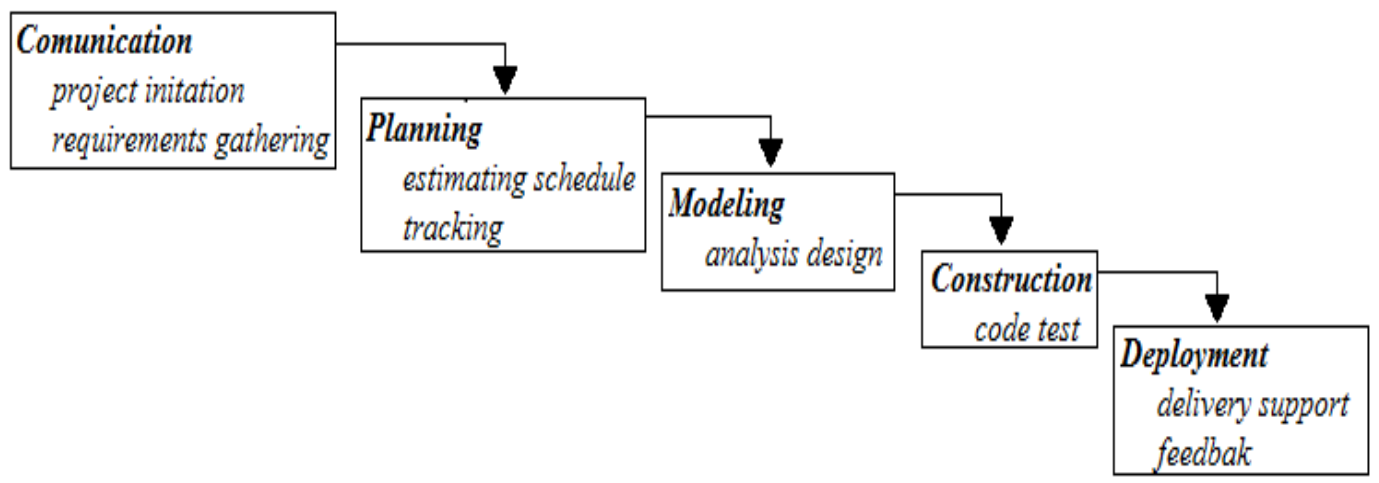

Gambar 1. Metode Waterfall

(Sumber: Pressman, 2015) 
Berikut ini adalah penjelasan dari tahapan-tahapan yang terdapat dalam metode Waterfall:

1. Comunication, merupakan pengumpulan kebutuhan data dari aplikasi penjualan yang akan di buat.

2. Planning, merupakan perencanaan akan tugas-tugas teknis yang akan dilakukan, resiko apa yang dapat terjadi, sumber daya yang diperlukan dalam membuat sistem, produk kerja yang ingin dihasilkan, penjadwalan kerja yang akan dilaksanakan dan tracking proses pengerjaan sistem.

3. Modeling, merupakan pemilihan dan analsis data yang telah di dapat untuk disesuaikan dengan kebutuhan aplikasi penjualan benih sayuran.

4. Construction, merupakan pengkodean menggunakan bahasa pemograman java dan menghubungkan data-data yang telah dibuat ke dalam rancangan form masukan dan form keluaran. Agar sistem aplikasi yang telah dibuat dapat berjalan dengan baik dan memberikan hasil yang optimal, maka perlu proses pengujian. Pengujian yang di gunakan adalah blackbox, dimana program dianggap sebagai suatu "blackbox", pengujian berbasiskan spesifikasi, kebenaran perangkat lunak yang diuji hanya dapat dilihat berdasarkan keluaran yang dihasilkan dari data atau kondisi masukan yang diberikan untuk fungsi yang ada tanpa melihat bagaimana proses untuk mendapatkan keluaran tersebut. Pengujian black box berusaha menemukan kesalahan dalam kategori:

a. Fungsi-fungsi yang tidak benar atau hilang

b. Kesalahan interface, kesalahan dalam tampilan layar

c. Kesalahan pada struktur data atau akses database

d. Kesalahan performansi, kesalahan inisialisasi dan tujuan akhir

5. Deployment, merupakan pengimplementasian aplikasi penjualan ini pada komputer yang dimiliki pada pengusaha industri. Sistem yang sudah terpasang pada komputer kemudian di input dengan data-data yang ada. Pada akhir implementasi aplikasi ini dilakukan kegiatan corrective maintance terhadap aplikasi penjualan, maka kesalahan-kesalahan tersebut dapat dievaluasikan dan di perbaiki. Tanggapan user dalam menjalankan aplikasi ini juga sangat diperlukan, sehingga aplikasi penjualan yang dibuat dapat mempermudah user dalam melakukan aktivitas transaksi sehari-hari.

\section{HASIL DAN PEMBAHASAN}

\section{Analisa Permasalahan}

Pada Sistem Informasi penjualan benih sayuran di UD Rumpun Tani ini masih konvensional belum terkomputersisasi. Pencatatan data transaksi penjualan dan data persediaan barang masih konvensional yaitu dilakukan secara tertulis. Proses transaksi penjualan yang kurang efektif dan efisien serta seringnya terjadi kesalahan dalam menjumlahkan total bayar karena masih menggunakan alat bantu seperti kalkulator. Pengelolaan persediaan barang yang belum terkontrol dengan baik sering menyebabkan terjadinya ketidakcocokan antara data barang yang dibeli dengan data barang yang tersedia, sehingga mempersulit dalam proses pencarian data barang maupun pembuatan laporan persediaan barang. Lambatnya proses rekapitulasi data transaksi penjualan dan data persediaan barang untuk dijadikan laporan.

\section{Alternatif Penyelesaian Masalah}

Berdasarkan analisis masalah yang terdapat pada UD Rumpun Tani, maka dapat disimpulkan alternatif penyelesaian masalah yang ada yaitu dengan membuat sistem informasi penjualan yang terintegerasi agar tidak terjadi keterlambatan di dalam proses pengerjaan informasi serta membuat sistem yang dapat mengolah data persediaan barang secara up to date untuk mengatasi terjadinya ketidakcocokan antara data barang yang dibeli dengan data barang yang tersedia agar mudahnya dalam mencari informasi persediaan barang juga pembuatan database sistem informasi penjualan yang memberikan keuntungan dalam penyimpanan data.

\section{Diagram Alir Data (DAD) Sistem yang Diusulkan}

DFD Menurut (Jogiyanto, 2015) mendefinisikan bahwa "data flow diagram yang menggunakan notasi-notasi untuk menggambarkan arus dari data sistem, yang penggunaannya sangat membantu untuk memahami sistem secara logika, terstruktur dan jelas". 
DFD adalah untuk menggambarkan sistem dari level yang paling tinggi kemudian menguraikannya menjadi level yang lebih rendah. DFD adalah suatu jaringan yang menggambarkan suatu sistem komputerisasi, manualisasi atau gabungan dari keduanya, yang penggambarannya disusun dalam bentuk kumpulan komponen sistem yang sakung berhubungan sesuai dengan aturan mainnya.

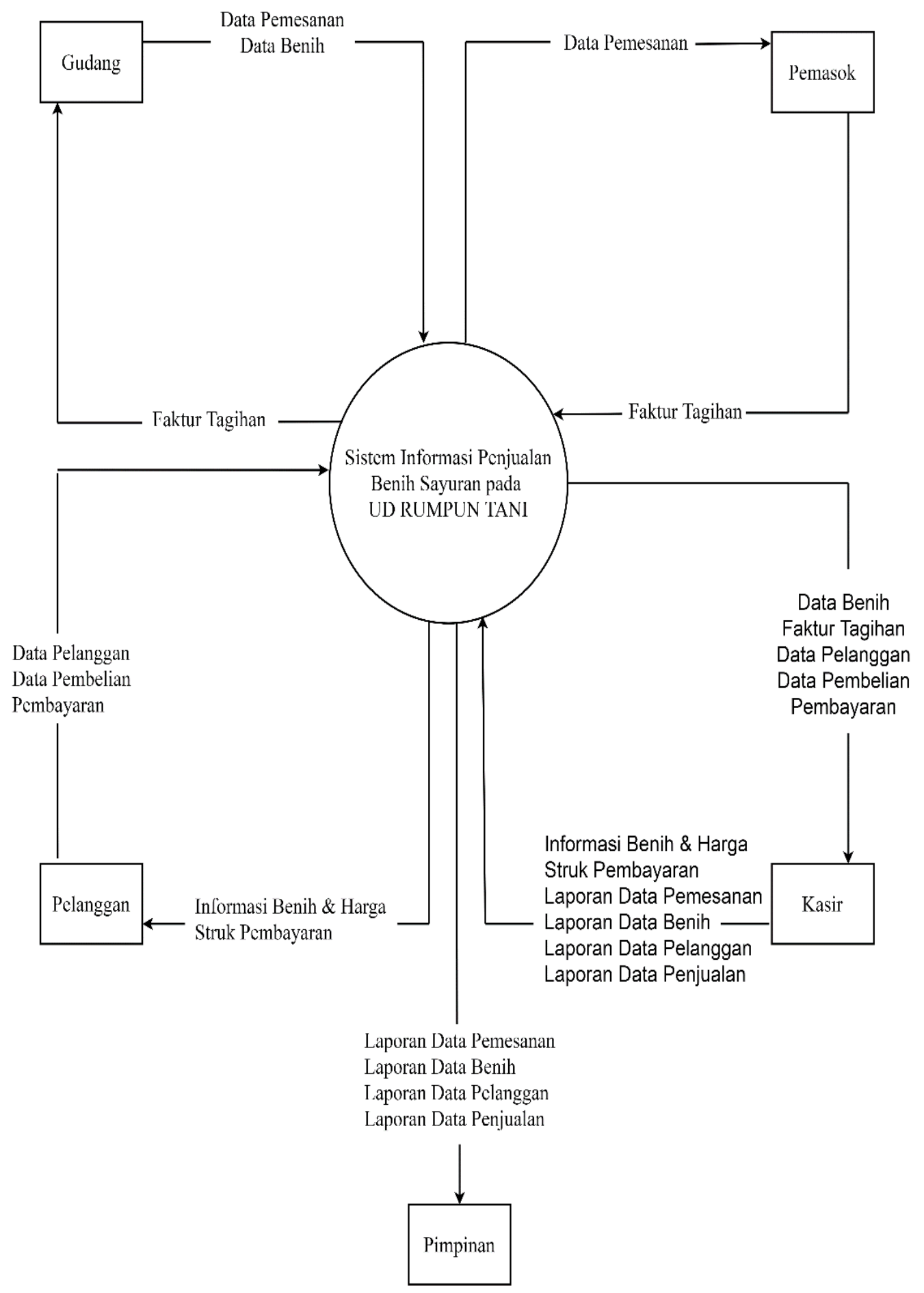

Gambar 2. Diagram Konteks 

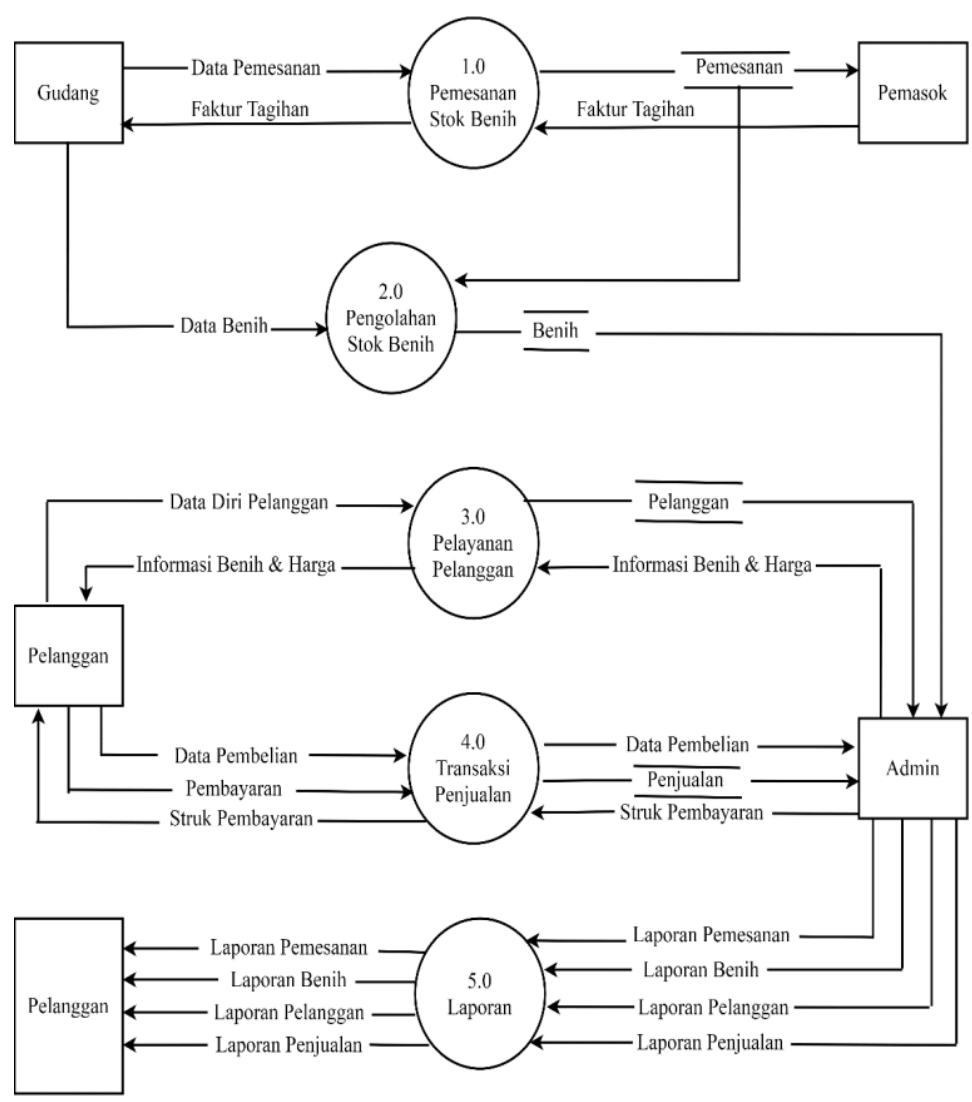

Gambar 3. Diagram Nol

\section{Tampilan Layar}

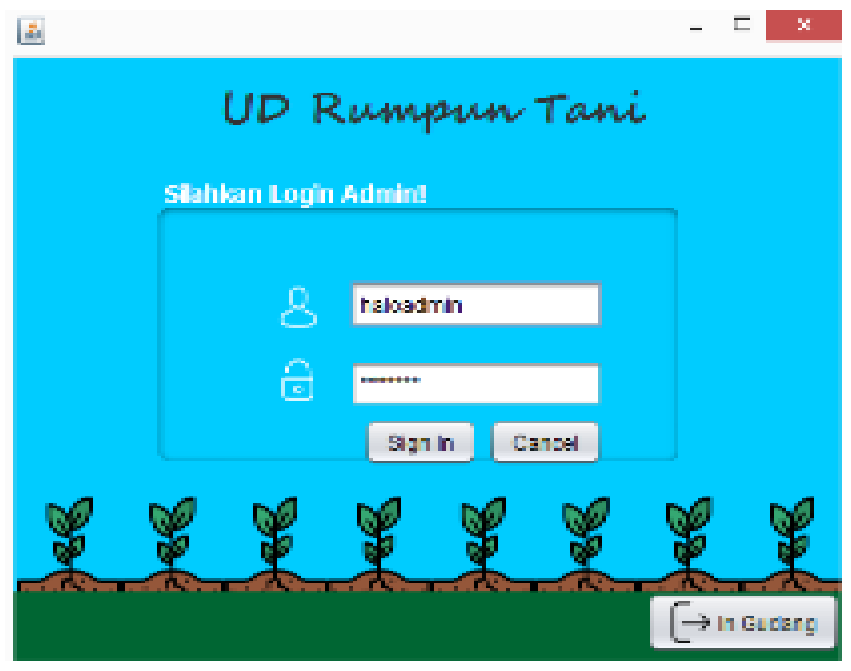

Gambar 4. Menu Login

Tampilan form Login ini muncul di awal saat pengoperasian program aplikasi penjualan benih sayuran UD. Rumpun Tani untuk diisi oleh admin sebagai user. Masukkan username dan password yang sesuai dengan hak akses supaya bisa mengoperasikan sistem aplikasi penjualan benih sayuran. Jika username dan password sesuai maka akan masuk ke tampilan menu utama admin. Jika ingin login sebagai gudang maka bisa klik button (In Gudang) di pojok bawah kanan pada menu form login di atas. 


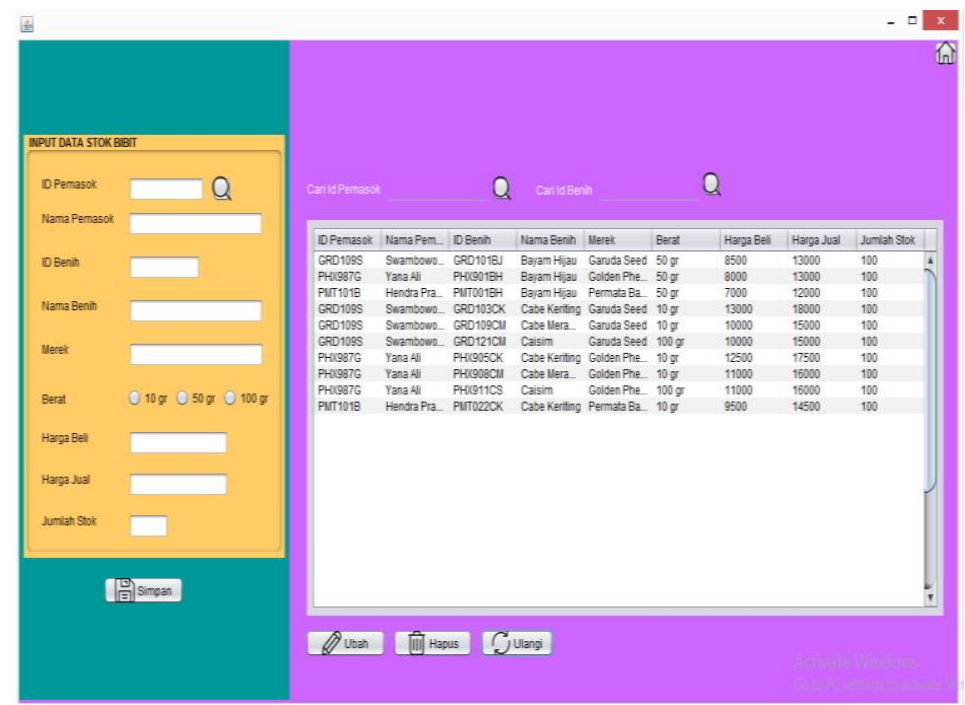

Gambar 5. Tampilan Layar Data Benih

Pada tampilan form masukan data benih ini, gudang sebagai user dapat melakukan penambahan, mengubah serta menghapus data benih. Masukan id benih lalu klik button cari untuk melakukan pengecekkan data-data yang sudah tersimpan pada data store benih. Menyediakan button simpan untuk menyimpan data benih baru, button ubah untuk mengubah data benih dan button hapus unuk menghapus data benih.

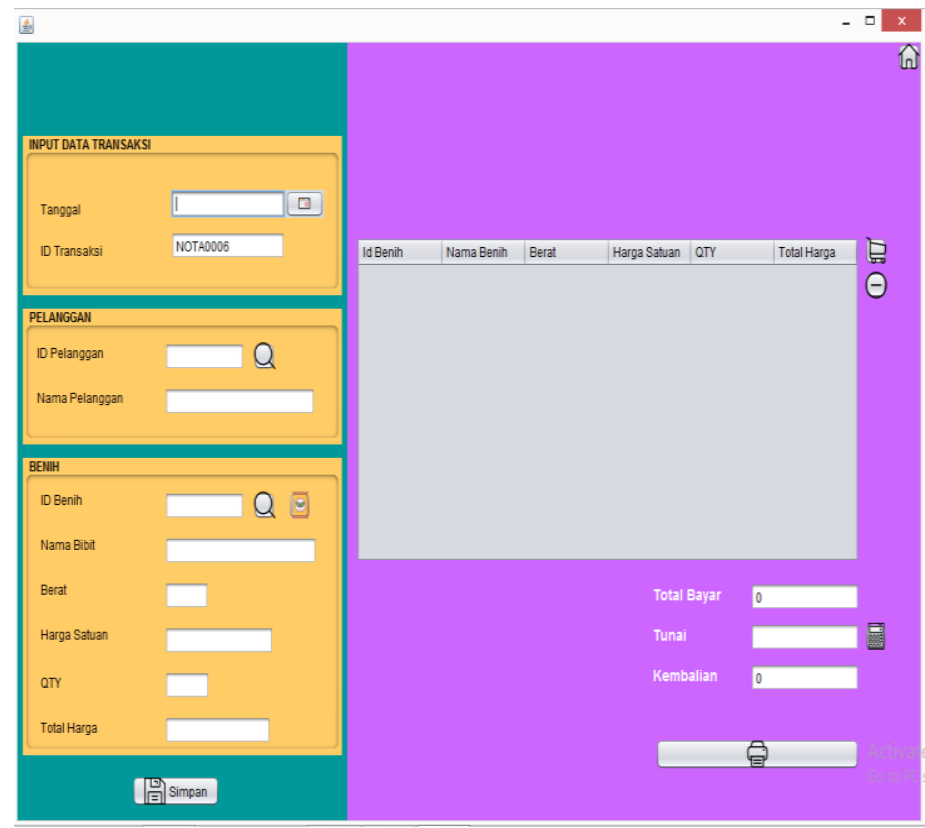

Gambar 6. Tampilan Layar Data Transaksi Penjualan

Pada tampilan form masukan data transaksi penjualan ini, admin sebagai user dapat melakukan penginputan data pembelian dan pembayaran yang akan dilakukan oleh pelanggan. Terdapat button data pelanggan untuk meload data pelanggan dan button data benih untuk meload data benih. Button keranjang untuk menambahkan list benih yang akan dibeli oleh pelanggan dan masuk ke dalam tabel. Button cancel untuk menghapus list benih yang sudah masuk kedalam tabel. Button simpan digunakan untuk menyimpan data agar muncul pada tabel penjualan. Button cetak untuk mencetak nota setelah penjualan selesai dilakukan. 


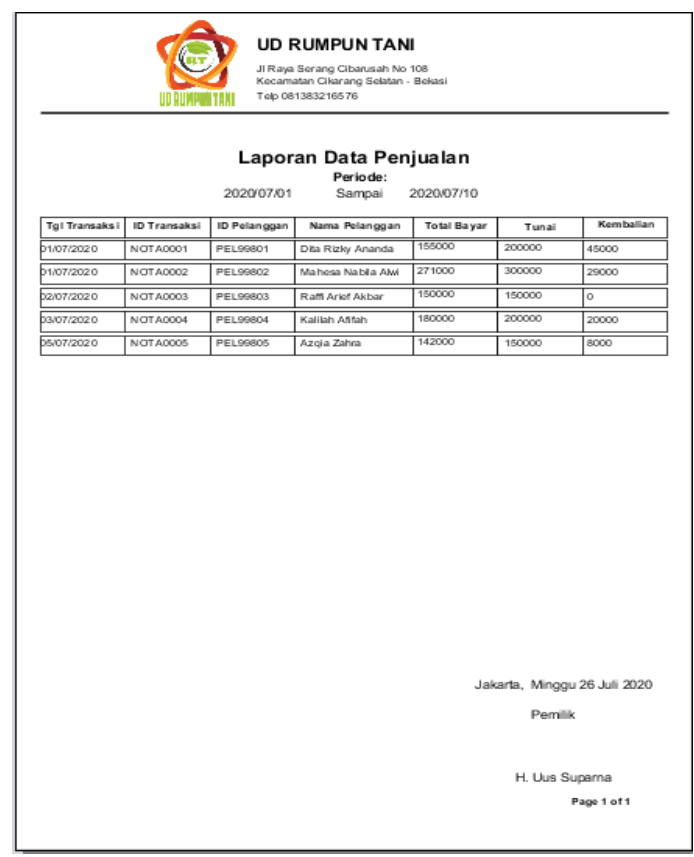

Gambar 7. Tampilan Laporan Data Penjualan

Pada tampilan laporan data penjualan benih ini berisikan data-data yang ada pada tabel penjualan. Laporan ini muncul ketika admin mengklik button laporan data penjualan pada tampilan menu utama admin. Admin bisa mencetak laporan ini dengan mengklik button cetak yang ada di bawah pojok kanan form data penjualan.

\section{SIMPULAN}

Simpulan yang dapat diambil dari penelitian ini yaitu dengan dirancangnya sistem informasi penjualan yang akan membantu menyelesaikan masalah dalam proses transaksi jual-beli yang terjadi pada UD. Rumpun Tani dengan menggunakan proses yang terkomputerisasi. Pengimplementasian Sistem Informasi Penjualan UD Rumpun Tani ini diharapkan dapat mengelola data dengan baik untuk mengefesienkan dan mengefektifkan proses pengolahan data stok dan penjualan pada UD Rumpun Tani serta dapat membantu meningkatkan penjualan pada UD Rumpun Tani.

\section{DAFTAR PUSTAKA}

Agusvianto, H. (2017). Sistem Informasi Inventori Gudang Untuk Mengontrol Persediaan Barang Pada Gudang Studi Kasus : PT.Alaisys Sidoarjo. JIEET (Journal of Information Engineering and Educational Technology), 40-46.

Hanhan Hanafiah Solihin, A. A. (2017). Rancang Bangun Sitem Informasi Penjualan, Pembelian dan Persediaan Suku Cadang pada Bengkel Tiga Motor Putra Garut. INFOTRONIK (Jurnal Teknologi Informasi dan Elektronika), $107-115$

Jogiyanto. (2015). Diambil kembali dari Kumpulan Pengertian: http://www.kumpulanpengertian.com /2015/04/pengertian-data-flow-diagram-dfd.html

Jogiyanto. (2016). Analisis dan Desain Sistem Informasi. Yogyakarta: Andi

Mauluddin Nakya Santini, S. (2017). Sistem Informasi Persediaan Dan Penjualan Barang Berbasis Desktop Di D-Net House. Jurnal UNIKOM.

Kadir, Abdul. (2014). Belajar Database Menggunakan MySQL. Yogyakarta: Andi

Kadir, Abdul. (2014). Pemrograman Database MySQL Untuk Pemula. Yogyakarta:Mediakom

Mujiati, H. (2014). Analisis Dan Perancangan Sistem Informasi Stok Obat Pada Apotek Arjowinangun Hanik Mujiati. Jurnal Informatika, 24-28.

Nurul Muthia, H. A. (2019). RANCANG BANGUN SISTEM INFORMASI AKUNTANSI PENJUALAN DENGAN MODEL WATERFALL BERBASIS JAVA DESKTOP. JITK (Jurnal Ilmu Pengetahuan dan Teknologi Komputer), 15-22.

Pressman. (2012). Pengantar Perancangan Sistem. Jakarta: Erlangga

Pressman, R. S. (2012). Rekayasa Perangkat Lunak.

Rini, N. (2010). Sistem Informasi Penjualan Barang pada Toko Sumber Urip. IT SMART. 